\title{
ANALISIS DERAJAT KONSOLIDASI BERDASARKAN HASIL PEMBACAAN PIEZOMETER PADA PROYEK TOL TRANS SUMATERA
}

\author{
Aditya Christiandi Sinulingga ${ }^{1}$, dan Andryan Suhendra² \\ ${ }^{1}$ Program Studi Sarjana Teknik Sipil, Universitas Tarumanagara, Jl. Letjen S. Parman No.1 Jakarta \\ adityachristiandi@gmail.com \\ ${ }^{2}$ Civil Engineering Department, Faculty of Engineering, Binus University, \\ Jl. K.H. Syahdan No. 9, Palmerah, Jakarta Barat 11480 \\ andryan@geosinindo.co.id; asuhendra@binus.ac.id
}

Masuk: 10-01-2021, revisi: 02-02-2021, diterima untuk diterbitkan: 11-03-2021

\begin{abstract}
The development of toll road or expressway infrastructure in Indonesia is urgently needed because it can reduce inefficiencies due to congestion on main sections, as well as to improve the process of distribution of goods and services, especially in areas with high levels of development. Transportation infrastructure development on soft soils often experiences consolidation decline problems. Soft soil has a high moisture content and low bearing capacity. If the soft soil is saturated with water, it means that the water cannot be fully dissipated, causing the soil to take a long time to consolidate. If the construction work does not begin with land improvement, the construction has the potential to suffer damage before the planned age. To anticipate this, an alternative that can be done is to repair the soil with prefabricated vertical drain (PVD) and vacuum preloading. This study aims to determine the degree of consolidation based on the piezometer reading and to make initial predictions. As for the results of this study there is a difference of 5.79\% in the degree of assessment from the results of theoretical calculations with the piezometer reading.
\end{abstract}

Keywords: consolidation, piezometer, vacuum preloading, prefabricated vertical drain (PVD).

\begin{abstract}
ABSTRAK
Pembangunan infrastruktur jalan tol atau jalan bebas hambatan di Indonesia sangat dibutuhkan karena dapat mengurangi inefisiensi akibat kemacetan pada ruas utama, serta untuk meningkatkan proses distribusi barang dan jasa terutama di wilayah yang sudah tinggi tingkat perkembangannya. Pembangunan infrastruktur transportasi pada tanah lunak sering mengalami masalah penurunan konsolidasi. Tanah lunak memiliki kadar air yang tinggi dan daya dukung yang rendah. Jika tanah lunak jenuh air mengakibatkan air tidak dapat terdispasi secara penuh menyebabkan tanah membutuhkan waktu yang lama untuk terkonsolidasi. Apabila pekerjaan konstruksi tidak diawali dengan perbaikan tanah maka konstruksi tersebut berpotensi mengalami kerusakan sebelum umur yang telah direncanakan. Untuk mengantisipasi hal tersebut alternatif yang dapat dilakukan adalah melakukan perbaikan tanah dengan prefabricated vertical drain (PVD) dan vacuum preloading. Penelitian ini bertujuan untuk mengetahui besar derajat konsolidasi berdasarkan pembacaan piezometer serta melakukan prediksi awal. Adapun hasil dari penelitian ini terdapat perbedaan 5,79\% derajat konsolidasi dari hasil perhitungan teoritis dengan pembacaan piezometer.
\end{abstract}

Kata kunci: konsolidasi, piezometer, vacuum preloading, prefabricated vertical drain (PVD).

\section{PENDAHULUAN}

Indonesia adalah negara yang mengalami peningkatan ekonomi yang pesat sehingga dibutuhkannya jalur distribusi produk ekonomi. Salah satu distribusi produk ekonomi tersebut dilakukan melalui transportasi darat. Jalan tol merupakan salah satu akses transportasi darat yang semakin berkembang di Indonesia. Jalan tol atau jalan bebas hambatan adalah suatu jalan yang dikhususkan untuk kendaraan bersumbu lebih dari dua (mobil, bus, truk) dan bertujuan untuk mempersingkat jarak dan waktu tempuh dari satu tempat ke tempat lain serta mengurangi kemacetan.

Pembangunan jalan di atas tanah lunak akan menghadapi beberapa masalah geoteknik. Seperti masalah konsolidasi yang cukup besar dan kekuatan daya dukung dalam menahan beban yang terjadi di atasnya. Keadaan 
tanah dasar demikian bila tidak ditangani dengan baik akan mempengaruhi kondisi badan jalan di atasnya dan akan mempercepat kerusakan jalan tersebut.

Batasan masalah yang dibahas pada analisis ini adalah:

1. Lokasi penelitian di jalan tol Sumatera.

2. Analisis derajat konsolidasi di lapangan berdasarkan pembacaan piezometer.

3. Penurunan yang ditinjau adalah penurunan konsolidasi primer.

4. Tidak memperhitungkan getaran.

5. Tidak memperhitungkan curah hujan.

6. Tidak memperhitungkan konsolidasi arah horizontal.

7. Data yang digunakan adalah hasil tes laboratorium, Boring log dan SPT serta hasil monitoring.

Rumusan masalah yang dibahas pada analisis ini adalah:

1. Besar derajat konsolidasi tanah berdasarkan pembacaan piezometer.

2. Perbandingan derajat konsolidasi berdasarkan piezometer dan prediksi awal.

Tujuan dari penelitian ini adalah:

1. Menghitung derajat konsolidasi tanah terjadi akibat berdasarkan pembacaan piezometer.

2. Membandingkan perbandingan derajat konsolidasi tanah berdasarkan piezometer dan prediksi awal.

\section{Tanah Lunak}

Tanah adalah ikatan antara butiran yang relatif lemah dapat disebabkan oleh karbonat, zat organik, atau oksidaoksida yang mengendap di antara partikel-partikel. Ruang di antara partikel-partikel dapat berisi air, udara, ataupun yang lainnya. (Hardiyatmo H. C., 1992)

Tanah lunak dalam konstruksi sering kali menjadi permasalahan. Hal ini disebabkan oleh rendahnya daya dukung tanah tersebut. Daya dukung yang rendah dapat menyebabkan kerugian, mulai dari kerugian dari sisi biaya konstruksi yang semakin mahal, hingga terancamnya keselamatan konstruksi, yaitu struktur yang dibuat tidak mampu berdiri secara stabil dan bisa roboh.

Pada kondisi tanah dasar berupa tanah lempung yang sangat lunak dengan kemampuan daya dukung yang relatif terbatas, sering kali dijumpai permasalahan berupa kelongsoran pada tanah dasar pada saat pengaplikasian pra beban, sehingga harus melakukan proses penimbunan secara bertahap sesuai dengan kemampuan daya dukung tanah dan sering kali membutuhkan waktu yang lama. (Andryan Suhendra, 2011)

\section{Penurunan Konsolidasi Tanah}

Penurunan konsolidasi adalah penurunan yang terjadi akibat terdisipasinya tegangan air pori dalam tanah dengan undrained menuju tanah dengan kondisi drained. Konsolidasi sebagai proses keluarnya air atau udara dari dalam pori tanah, deformasi partikel tanah, serta relokasi partikel yang disebabkan oleh beban tambahan pada tanah. (Das B. M., 1985)

Penambahan beban di atas permukaan tanah dapat menyebabkan lapisan di bawah mengalami pemampatan. Pemampatan disebabkan adanya keluarnya air dan udara dalam pori, relokasi partikel, dan sebab-sebab lainnya (Hardiyatmo H. , 1994).

Untuk perhitungan penurunan konsolidasi, formula yang digunakan dapat berbeda-beda sesuai dengan persyaratan yang berlaku. Jika $\mathrm{P}_{\mathrm{c}}<\mathrm{P}_{\mathrm{o}}$ maka digunakan formula berikut.

$$
S_{c}=\frac{C c H}{1+e_{o}} \log \frac{P_{o}+\Delta p}{P_{o}}
$$

dengan $\mathrm{H}=$ ketebalan lapisan tanah yang ditinjau, $\mathrm{e}_{\mathrm{o}}=$ initial void ratio, $\mathrm{Cc}=$ koefisien kompresibilitas, $\mathrm{P}_{\mathrm{o}}=$ tegangan efektif tanah pada permukaan lapisan tanah yang ditinjau, $\Delta p=$ tekanan fondasi netto.

Jika $\mathrm{P}_{\mathrm{o}}<\mathrm{P}_{\mathrm{C}}<\mathrm{P}_{\mathrm{o}}+\Delta p$ maka digunakan formula berikut.

$$
S_{c}=\frac{H}{1+e_{o}}\left(\operatorname{Cs} \log \frac{P_{c}}{P_{o}}+\operatorname{Cc} \log \frac{P_{o}+\Delta p}{P_{C}}\right)
$$

dengan $\mathrm{H}=$ ketebalan lapisan tanah yang ditinjau, $\mathrm{e}_{\mathrm{o}}=$ initial void ratio, $\mathrm{Cs}=$ koefisien rekompresibilitas, $\mathrm{P}_{\mathrm{c}}=$ tegangan kompresibilitas, $\mathrm{P}_{\mathrm{o}}=$ tegangan efektif tanah pada permukaan lapisan tanah yang ditinjau, Cc $=$ koefisien kompresibilitas, $\Delta p=$ tekanan fondasi netto. 
Jika $\mathrm{P}_{\mathrm{o}}+\Delta p<\mathrm{P}_{\mathrm{c}}$ maka digunakan formula berikut.

$$
S_{c}=\frac{C s H}{1+e_{o}} \log \frac{P_{o}+\Delta p}{P_{o}}
$$

dengan $\mathrm{H}=$ ketebalan lapisan tanah yang ditinjau, $\mathrm{e}_{\mathrm{o}}=$ initial void ratio, $\mathrm{Cs}=$ koefisien rekompresibilitas, $\mathrm{P}_{\mathrm{o}}=$ tegangan efektif tanah pada permukaan lapisan tanah yang ditinjau, $\Delta p=$ tekanan fondasi netto.

\section{Perencanaan Prefabricated Vertical Drain (PVD)}

Pemampatan yang dilakukan membutuhkan waktu yang sangat lama, maka dibutuhkan percepatan dalam pemampatan tanah. Salah satu metode perbaikan tanah untuk mempercepat waktu konsolidasi adalah dengan menggunakan Vertical Drain. Vertical drain dapat diklasifikasikan menjadi 3 (tiga) tipe umum, yaitu : sand drain, fabric encased drain, dan prefabricated vertical drain (PVD). Adapun untuk PVD itu sendiri bisa berupa karton, textile, plastik, atau material lainnya (bahan karung dan sabut kelapa). Pada umumnya PVD banyak digunakan karena kemudahan pemasangan di lapangan. Tiang-tiang atau lubang-lubang tersebut "dipasang" di dalam tanah pada jarak tertentu sehingga memperpendek jarak aliran drainase air pori (drainage path) (Mochtar, 2000)

PVD berperan besar dalam proses konsolidasi. Dengan menggunakan PVD, maka proses konsolidasi dapat berjalan lebih cepat. Metode perbaikan tanah dengan menggunakan vertical drain intinya adalah untuk mereduksi waktu antara dua fase pelaksanaan di saat dilakukannya penimbunan bertahap dan mengurangi waktu yang diperlukan untuk memperoleh derajat konsolidasi. Bentuk susunan PVD dapat berupa pola bujur sangkar Gambar 1 dan pola segitiga Gambar 2.
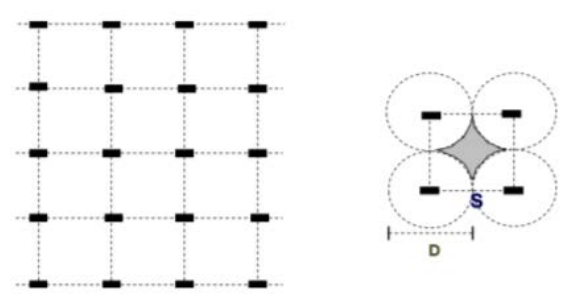

Gambar 1. Pola susunan PVD bujur sangkar (Mochtar, 2000)
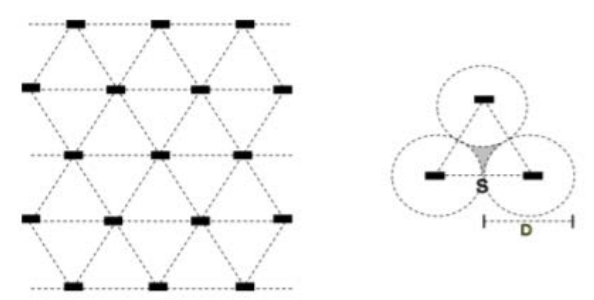

Gambar 2. Pola susunan PVD segitiga (Mochtar, 2000)

Untuk pola susunan bujur sangkar:

$$
D=1.13 \times S
$$

Untuk pola susunan segitiga:

$$
D=1.05 \times S
$$

dengan $D=$ diameter pengaruh satu PVD (m), dan $S=$ spacing atau jarak antar PVD

\section{Penentuan Derajat Konsolidasi dengan Menggunakan PVD}

Dengan adanya drainase vertikal pada lapisan tanah, maka tegangan pori berlebih akan terdisipasi dalam 2 arah, yaitu arah vertikal dan arah horizontal. Sehingga nilai derajat konsolidasi total (U) dapat dihitung melalui persamaan berikut

$$
U=1-\left(1-U_{h}\right)\left(1-U_{v}\right)
$$

dengan $U_{h}=$ derajat konsolidasi arah vertikal, dan $U_{v}=$ derajat konsolidasi arah horizontal 
Harga derajat konsolidasi horizontal $U_{h}$ dapat dicari dengan memasukan nilai t (waktu) tertentu dengan persamaan berikut

$$
\begin{gathered}
T_{h}=\frac{C_{h} \times t}{D^{2}} \\
U_{h}=1-\exp \left(\frac{-8 T_{h}}{F_{n}}\right)
\end{gathered}
$$

Harga derajat konsolidasi vertikal $U_{v}$ dapat dicari dengan masukan nilai t (waktu) tertentu

$$
\begin{gathered}
T_{v}=\frac{t \cdot C_{v}}{\left(H_{d r}\right)^{2}} \\
U_{v}=\left(2 \sqrt{\frac{T_{v}}{\pi}}\right)
\end{gathered}
$$

dengan $T_{h}=$ faktor waktu arah horizontal, dan $T_{v}=$ faktor waktu arah vertikal

\section{METODE PENELITIAN}

Alur atau tahapan dari penelitian ini tertera dalam bentuk diagram pada Gambar

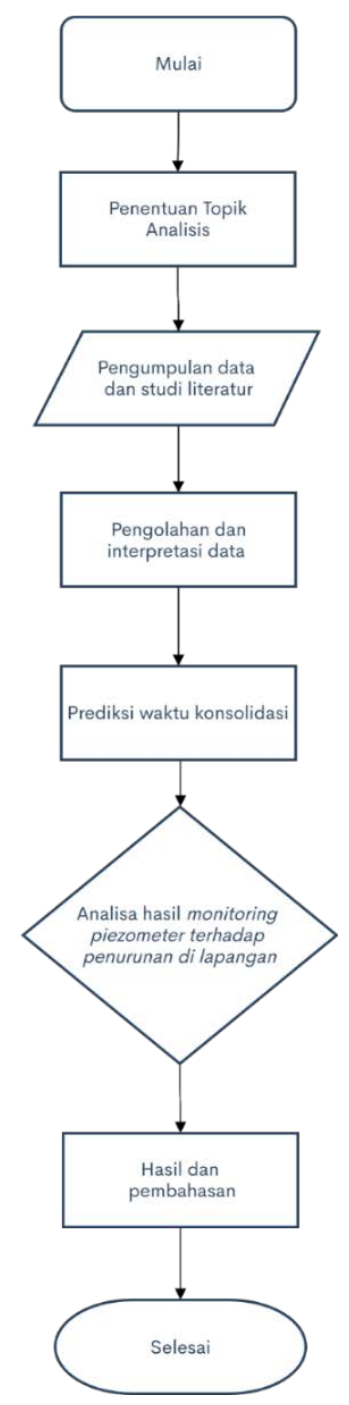

Gambar 3. Diagram bagan alir 
Pada penelitian ini seperti terlihat pada gambar 3, dimulai dari penentuan topik analisis, kemudian mengumpulkan data. Pengumpulan data dengan menggunakan data sondir, laboratorium, dan monitoring. Apabila data kurang lengkap maka dilakukan korelasi data tanah dengan parameter-parameter yang ada. Berdasarkan data dan parameter tanah yang sudah dimiliki kemudian dilakukan pengolahan dan interpretasi data. Kemudian dilakukan perhitungan untuk memprediksi derajat konsolidasi. Setelah itu membandingkan derajat konsolidasi dari hasil monitoring piezometer dengan prediksi awal.

\section{HASIL DAN PEMBAHASAN}

\section{Data Material dan Pemasangan PVD}

Vertical drains dipasang pada area dengan rincian pemasangan sebagai berikut:

- Kedalaman pemasangan : $12 \mathrm{~m}$

- Pola pemsangan : persegi

- Lebar vertical drains (a) : $100 \mathrm{~mm}$

- Jarak antar PVD (s) : $1 \mathrm{~m}$

\section{Prediksi Awal Penurunan Konsolidasi Total}

Prediksi penurunan yang terjadi dihitung berdasarkan one dimensional settlement. Konsolidasi tanah adalah over consolidated yaitu dimana $\sigma_{c}{ }^{\prime}>\sigma_{0}{ }^{\prime}$, oleh karena itu besar penurunan dapat dihitung dengan persamaan (1), sehingga dapat prediksi penurunan konsolidasi total tiap zona terdapat pada tabel 1.

Tabel 1. Penurunan Sc

\begin{tabular}{cc}
\hline Zona & Penurunan Sc $(\mathrm{m})$ \\
\hline Zona 1 & 0,3563 \\
Zona 2 & 0,3786 \\
Zona 3 & 0,3686 \\
Zona 4 & 0,2569 \\
Zona 5 & 0,3193 \\
Zona 6 & 0,2947 \\
Zona 7 & 0,3076 \\
\hline
\end{tabular}

\section{Prediksi Awal Derajat Konsolidasi}

Pada saat penimbunan vacuum, vertical drains telah dipasang oleh karena itu perhitungan derajat konsolidasi sudah menggunakan persamaan-persamaan yang berhubungan dengan dengan vertical drains. Dengan jarak pemasangan vertical drains satu meter didapat zona pengaruhnya adalah 1,13 meter. Vertical drains yang digunakan merupakan jenis yang lebar 0,1 m dengan ketebalan 0,004 m. Dari data yang diketahui dapat dihitung nilai diameter well dan faktor jarak drain $F_{n}$.

Berdasarkan nilai-nilai yang telah diperoleh dari perhitungan di atas, maka dapat dicari pengaruh dari vertical drains yaitu faktor dan derajat konsolidasi untuk drainase arah radial horizontal dan vertikal sehingga dapat diketahui derajat konsolidasi yang terjadi pada selang waktu tertentu. Kemudian dilakukan perhitungan derajat konsolidasi saat proses 60 hari dengan asumsi $\mathrm{Ch}=2 \mathrm{Cv}, \mathrm{Ch}=0,0432 \mathrm{~m}^{2} /$ hari. Berdasarkan perhitungan tersebut didapat nilai derajat konsolidasi saat 60 hari 99,96\%.

\section{Penentuan Derajat Konsolidasi Aktual}

Derajat konsolidasi juga dapat ditentukan melalui bacaan piezometer. Satu piezometer diletakkan pada setiap zona. Terdapat 7 zona jadi ada sebanyak 7 pembacaan piezometer. Dari bacaan rata-rata piezometer PP-01 Gambar 4, dapat dilihat bahwa puncak tegangan air pori berlebih adalah sebesar 127,799 $\mathrm{kPa}$. Lewat bacaan tersebut dapat dihitung derajat konsolidasi yang tercapai setelah pemasangan piezometer PP-01 adalah 95,1256\% 


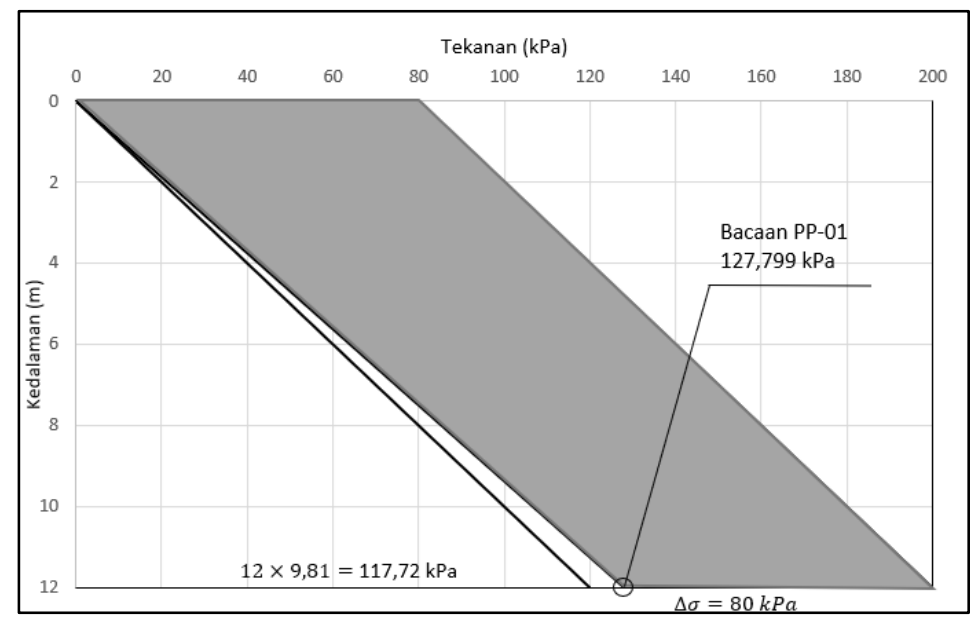

Gambar 4. Grafik kelebihan tegangan air pori PP-01

Perhitungan juga dilakukan pada PP-02, PP-03, PP-04, PP-05, PP-06, dan PP-07. Terlihat pada tabel 2.

Tabel 2. Derajat konsolidasi berdasarkan pembacaan piezometer

\begin{tabular}{cc}
\hline Zona & Derajat Konsolidasi (\%) \\
\hline Zona 1 & 95,1256 \\
Zona 2 & 94,4619 \\
Zona 3 & 93,7463 \\
Zona 4 & 93,8903 \\
Zona 5 & 94,5894 \\
Zona 6 & 94,6108 \\
Zona 7 & 92,7531 \\
\hline Rata-rata & 94,1682 \\
\hline
\end{tabular}

Berdasarkan perhitungan teoritis di dapat derajat konsolidasi sebesar 99,96\%. Terdapat perbedaan 5,79\% derajat konsolidasi dari hasil perhitungan teoritis rata rata dengan pembacaan piezometer.

\section{Analisis Balik Parameter Tanah}

Perhitungan analisis balik meliputi parameter tanah koefisien tanah horizontal $C_{h}$. Dapat diketahui nilai $C_{h}$ untuk dimasukkan ke dalam persamaan.

Karena $U_{v}$ itu relatif kecil kontribusinya maka dalam analisis berikut ini kontribusi $U_{v}$ tidak diperhitungkan. Sehingga di lakukan analisis balik dan mendapat perbandingan $C_{h /} C_{v}$ pada tabel 3 .

Tabel 3. Analisis balik parameter $\mathrm{Ch}$

\begin{tabular}{cccc}
\hline Zona & Th & Ch & Ch/Cv \\
\hline Zona 1 & 0,7884 & 0,0167 & 0,78 \\
Zona 2 & 0,7549 & 0,0160 & 0,74 \\
Zona 3 & 0,7232 & 0,0153 & 0,71 \\
Zona 4 & 0,7293 & 0,0155 & 0,72 \\
Zona 5 & 0,7610 & 0,0162 & 0,75 \\
Zona 6 & 0,7620 & 0,0162 & 0,75 \\
Zona 7 & 0,6847 & 0,0146 & 0,67 \\
\hline
\end{tabular}




\section{KESIMPULAN DAN SARAN}

\section{Kesimpulan}

Berdasarkan hasil dari analisis yang telah dilakukan pada penelitian ini, penulis menemukan beberapa kesimpulan sebagai berikut:

1. Tanah merupakan tanah over consolidated yaitu dimana $P_{c}{ }^{\prime}>P_{0}{ }^{\prime}$ menggunakan data hasil laboratorium.

2. Berdasarkan perhitungan teoritis diperoleh penurunan sebesar 256,9 mm - 378,6 mm.

3. Pemasangan PVD dengan kedalaman 12 meter, lebar vertical drain $100 \mathrm{~mm}$, dan ketebalan vertical drain 4 mm. PVD menggunakan pola segi empat dengan jarak 1 meter.

4. Derajat konsolidasi yang didapat dari metode teoritis sebesar 99,96\%. Sedangkan pembacaan piezometer didapat hasil derajat konsolidasi sebesar 94,17\%. Terdapat perbedaan 5,79\% derajat konsolidasi dari hasil perhitungan teoritis dengan pembacaan piezometer.

5. Karena adanya perbedaan derajat konsolidasi berdasarkan teoritis dan bacaan piezometer. Maka dilakukan perhitungan analisis balik, sehingga diperoleh koreksi nilai $\mathrm{Ch}=0,67 \mathrm{Cv}-0,78 \mathrm{Cv}$.

\section{Saran}

Saran dari analisis yang penulis lakukan adalah sebagai berikut:

1. Hasil perhitungan dibandingkan dengan metode lain seperti metode asaoka dan program elemen hingga.

2. Sebaiknya menggunakan data tanah hasil uji laboratorium agar hasil analisis lebih tepat daripada menggunakan hasil dari korelasi.

3. Perencanaan perbaikan tanah menggunakan PVD dicoba dengan kedalaman tanah yang berbeda seperti $1 / 2$ atau 2/3 dari kedalaman rencana penulis supaya didapatkan perencanaan PVD yang lebih efisien.

\section{DAFTAR PUSTAKA}

Suhendra,A dan Irsyam,M. "Studi Aplikasi Vacuum Preloading sbagai Metode Alternatif Percepatan Proses Konsolidasi pada Tanah Lempung Lunak Jenuh Air: Trial GVS pada Perumahan Pantai Indah Kapuk, Jakarta.” ComTech Vol.2 (2011).

Das, Braja M. (translated by Mochtar N.E, and Mochtar I.B.). Mekanika Tanah (Prinsip-Prinsip Rekayasa Geoteknik) Jilid I. Jakarta: Erlangga, 1985.

Hardiyatmo, H.C. Mekanika Tanah 2. Jakarta: P.T. Gramedia Pustaka Utama, 1994.

Hardiyatmo, Hary Christady, and Prihminto Widodo. Mekanika Tanah. Jakarta: Gramedia Pustaka Utama, 1992.

Mochtar, Indrasurya B. Teknologi Perbaikan Tanah dan Alternatif Perencanaan pada Tanah Bermasalah. Surabaya: Jurusan Teknik Sipil FTSP-ITS, 2000. 

